\title{
Perceptions of local hospitals and food producers on opportunities for and barriers to implementing farm-to-hospital programs
}

\author{
Allie Perline a $*$ \\ University of Montana \\ Annie Heuscher ${ }^{b}$ \\ Community Food \& Agriculture Coalition \\ Annie Sondag ${ }^{\mathrm{c}}$ and Blakely Brown ${ }^{\mathrm{c}}$ \\ University of Montana
}

Submitted June 25, 2015 / Revised September 9, 2015 / Accepted September 28, 2015 /

Published online December 17, 2015

Citation: Perline, A., Heuscher, A., Sondag, A., \& Brown, B. (2015). Perceptions of local hospitals and

food producers on opportunities for and barriers to implementing farm-to-hospital programs. Journal

of Agriculture, Food Systems, and Community Development, 6(1), 147-159.

http://dx.doi.org/10.5304/jafscd.2015.061.015

Copyright (C) 2015 by New Leaf Associates, Inc.

\begin{abstract}
The farm-to-table movement has significantly increased in the United States during the last decade. More locally sourced foods are being used in meal programs on a larger, institutional scale. Farm-to-hospital initiatives have been emerging as

a* Corresponding author: Allie Perline, Department of Health \& Human Performance, University of Montana; 32 Campus Drive; Missoula, Montana 59812 USA.

Allie Perline can be contacted at $+1-802-233-4351$ or allieperline@gmail.com

b Annie Heuscher, Community Food \& Agriculture Coalition; P.O. Box 7025; Missoula, Montana 59807 USA; annie@missoulacfac.org
\end{abstract}

${ }^{\mathrm{c}}$ Department of Health \& Human Performance, University of Montana; 32 Campus Drive; Missoula, Montana 59812 USA; annie.sondag@umontana.edu; blakely.brown@umontana.edu an effort to reestablish local, healthy diets into the health care model. As a result, barriers, opportunities, and capacity-building strategies specific to farm-to-hospital initiatives are being more closely explored. The purpose of this study is to investigate perceptions and attitudes of local food producers and hospital staff towards using locally sourced foods in hospital food service programs. To identify these perceptions, in-depth interviews were conducted with staff involved with food procurement and management at two Montana hospitals and with local food producers and distributors. Barriers for hospitals to use locally sourced foods included price, product availability, and quantity, while opportunities included positive relationships, product quality, and champion leaders of the local food system movement within the hospital setting. Furthermore, capacity-building 
strategies suggested by the interviews included development of cooperative distribution of local foods and formalized working-relationship contracts. Most significantly, collaborative dialogue was identified as a method to further support the extent of locally sourced foods being used in hospital food service programs.

\section{Keywords}

Farm-to-hospital, local food systems, qualitative research, farm-to-institution, hospital food service

\section{Introduction and Background}

To increase food availability and to meet growing demand on a global scale, food production and distribution shifted away from small local businesses to a larger, industrialized system during the 1930s and 40s (Lobao \& Stofferahn, 2007).

Throughout this period, farm production transformed to emphasize specialization, standardization, and consolidation in order to enhance productivity and economic efficiency (Ikerd, 2009). Although food production increased, growing monopolization of the food system eventually spurred a nationwide movement to revitalize local, community-based food systems (Lyson \& Green, 1999). Locally based initiatives and direct marketing arrangements gained significant momentum by the 1990s in efforts to reconnect communities with the food production and distribution processes. Direct marketing arrangements, such as farmers markets and community-supported agriculture (CSA), are reviving working partnerships between food producers and food consumers. Building on these initiatives, local farmers are now connecting with schools, local restaurants, grocery stores, and other institutions (Dauner et al., 2011).

As the local food movement continues to grow, opportunities and challenges involving locally grown food in institutional settings are emerging. Kloppenburg, Wubben, and Grunes (2008) conducted a literature review on the implementation of farm-to-school programs and assessed the Wisconsin Homegrown Lunch program in three schools of the Madison Metropolitan School District. Three core challenges that emerged around implementation of a farm-toschool program pertained to cost, procurement, and supply, all closely reflecting challenges identified in the literature and other assessment studies. Gregoire, Arendt and Strohbehn (2005) surveyed 151 local food producers on perceived benefits and challenges of working with local restaurants. Producers identified support for local farmers, delivery of fresher food, and shorter travel distance as benefits that result from working with restaurants; the greatest challenges included year-round availability of products, lack of dependable demand, communication with institutions, and ability to fulfill quantity demands (Gregoire et al., 2005).

The health care system is emerging as a significant leader in developing relationships between healthy, sustainable food systems and healthy communities. Increasingly, health care facilities are choosing to model healthy food choices and environments as they engage in farm-to-hospital programs (Cohen, 2006; Dauner et al., 2011). Onsite farmers markets and stands are being implemented in hospitals across the country in order to better serve patients, staff, and the wider community (Kulick, 2005), and are already demonstrating positive health impacts. Kaiser Permanente has been hosting farmers markets at its medical campuses since 2003 across four states. In $2010 \mathrm{a}$ survey of over 2,400 market patrons was conducted at 37 Kaiser Permanente locations; 74 percent reported eating more fruits and vegetables as a result of attending the market (Cromp et. al, 2012). Another example of successful on-site farmers market programs is a market initiative that the National Institute of Health in Maryland has hosted for over 20 years. Duke University Medical Center offers a stand for employees, and Allen Memorial Hospital in Iowa offers a farmers market open to hospital staff and patients, as well as to the general public and surrounding community (Kulick, 2005). An emphasis on healthy diet is also changing food service programs in various ways, such as eliminating deep fat fryers, using organic produce and $\mathrm{rBGH}$-free milk, and substituting beef for leaner alternatives such as bison (Kulick, 2005).

As health care facilities more deeply explore farm-to-hospital programs, challenges and opportunities are emerging that often reflect those of other farm-to-institution initiatives. Dauner and her colleagues explored barriers and opportunities 
in using and procuring local foods in health care settings, in a study consisting of 25 semi-structured interviews with individuals in food acquisition, preparation, and service. Barriers included meeting quantity demands, restrictions due to contracts with group purchasing organizations (GPO), and lack of human, physical, and financial resources necessary to procure and prepare local-food ingredients from multiple producers and distributors (Dauner et al., 2011). A survey of 105 Ohio hospital food service directors (Raison \& Scheer, 2015) identified similar challenges to incorporating local foods into meals. Both food service directors using local foods in their operations and directors not currently using local foods highlighted the quality of local food items as a top concern. Meeting large quantity demands, restrictive GPO contracts, food safety protocol, and delivery and shipment sizes were also identified as challenges to using local foods in service meals (Raison \& Scheer, 2015).

Although hospitals are facing challenges to adopting more locally based food service meal programs, opportunities are also being identified that support farm-to-hospital programs. For example, opportunities identified by Dauner and her colleagues included food purchasing and preparation based on shared responsibility, effective communication, and teamwork (2011). Organization and community support for using locally grown foods, along with interest and commitment of food managers, were also identified as opportunities or facilitators of change (Dauner et al., 2011). Further supporting community-wide commitment as an opportunity in farm-to-hospital initiatives, Conner and his colleagues (2014) specifically explored the impact of shared values among farmers, distributors, and institutions in facilitating farm-to-institution (FTI) efforts. Semistructured interviews were conducted with Vermont farmers and distributor and buyer supplychain actors in FTI programs; results suggested that supply-chain actors with similar values are more flexible and creative in facilitating successful FTI programs (Conner, Sevoian, Heiss, \& Berlin, 2014).

Farm-to-hospital initiatives are relatively new. Thus, there has been limited assessment and evaluation of these initiatives and associated opportu- nities and challenges. Additionally, studies with these kinds of goals primarily utilize surveys and other forms of questionnaires. The focus tends to be either on perceptions of producers or perceptions of institutions, rather than an integrated analysis between these groups. Therefore, the purpose of this study was to compare and contrast both the perceptions of food producers and distributors, as well as hospital staff involved in food procurement and management. Through comparing and contrasting these perceptions, barriers and opportunities for locally sourced foods in food service meals were identified, along with culturally relevant capacity-building strategies, as informed by the data, that further support use of local ingredients in food service meals.

\section{Community Profile}

Montana is ranked fourth in size, but forty-eighth in population density of the 50 states. There are a wide variety of food growers and producers in Montana; many are located in Missoula County in northwestern Montana, producing crops that include produce, dairy, meats, flowers, and other artisanal products. There are various initiatives for supporting local producers and agriculture in Missoula, such as farmers markets, community gardens, food co-ops, CSAs, and farm-to-school programs. The Western Montana Grower's Cooperative (WMGC) supports local food producers by expanding their access to Montana markets. The WMGC is based on a cooperative (co-op) model: particular food items grown by participating members are aggregated and then distributed to meet the needs of purchasing institutions. This approach enables small producers to offer the larger quantities that institutions require. As a result, the WMGC creates opportunities for individual producers to work with institutions that otherwise might not be feasible due to the small scale of production on local farms. Another Montana resource for food producers is the Mission Mountain Food Enterprise Center (MMFEC), a food processing facility in northwest Montana. The MMFEC provides equipment and facilities for small, start-up producers to process or freeze their products before delivering orders to an institution. This infrastructure allows producers to process and 
sell "seconds," or products with visual imperfections - but that are more than adequate for consumption - which otherwise would not be sold at farmers markets or grocery stores.

There are two primary care hospitals in Missoula: St. Patrick Hospital and Community Medical Center. St. Patrick Hospital has 253 licensed beds and admitted nearly 8,000 patients in 2011 (St. Patrick Hospital, n.d.). St. Patrick is the only health care facility in Montana that has signed the Healthy Food in Health Care Pledge, and through its Green 4 Good campaign it practices a variety of guiding principles supporting environmental stewardship. St. Patrick Hospital also participates in a staff community supported agriculture (CSA) program. Community Medical Center has 151 acute-care beds and nearly 5,000 patients are admitted each year (Community Medical Center, n.d.-a). The facility advocates a connection between nutrition and a person's overall health and well-being. A commitment to this connection is supported through the hospital's Big Sky Café, which sources local dairy products, breads, beef and seasonal produce for its food service program (Community Medical Center, n.d.-b).

\section{Methods}

This study used a qualitative research design to engage hospital staff and food producers and distributors in identifying opportunities and barriers to using locally sourced foods in hospital food service programs. The University of Montana and Community Medical Center Institutional Review Boards jointly approved the study. Researcher Perline conducted interviews with staff knowledgeable about food procurement and management at the hospitals, along with local food producers and distributors in Missoula, Montana, from January 2014 to March 2014. Initially, key informants at both hospitals and a local food policy organization helped the researcher connect with staff knowledgeable about the management of the hospital food service programs or sustainability efforts and with local food producers and distributors. These individuals were then recruited to the study. Additional interviewees were recruited through convenience sampling, in which participants were recruited based on accessibility, and snowball sampling, in which participants initially chosen for the sample were used as informants to locate other participants fitting the criteria of the study (Penrod, Preston, Cain, \& Starks, 2003).

Prior to facilitating the interviews, the researcher received training in qualitative methods, including conducting mock interviews followed by feedback. The research team constructed two moderator's guides, one tailored for hospital staff and one for food producers and distributors. Each guide included 16 open-ended questions based on themes identified in the literature for farm-toschool programs and challenges and enhancements for using locally grown foods in non-school-based institutions. Authors Brown and Perline, who are trained in qualitative research, reviewed the guides. Examples of the 16 questions include the following:

If there was an interest in increasing the amount of local ingredients used in food service meals, how easy or difficult do you think it would be to do this?

Have you, or someone you know, had an experience in this hospital working with any local food producers or distributors? What was this experience like?

Can you describe an experience in which you have, or tried to have, a working relationship with an institution?

What, if any, kind of changes or resources would be needed to make a partnership with one of the hospitals or another institution more accessible or feasible?

The moderator guides also included discussion rules, recommendations for probing, and a time sequence.

Audiotapes and session notes were transcribed immediately following each interview and formed the basis for analysis. (The authors have corrected minor grammatical inaccuracies in the quotes presented here to illustrate the themes.) Authors Brown and Perline constructed coding categories based on the inductive methods of grounded 
theory, as described by Ulin, Robinson, and Tolley (2005). To construct the initial coding scheme, author Perline read all the interviews and developed a draft-coding frame. Microsoft Excel was used to conduct a coding sort in which similarly coded blocks of text were grouped together. This allowed the researcher to determine the frequency with which coded blocks appeared in the data set as a whole. Another researcher trained in qualitative research methods applied the initial coding frame to 30 randomly selected transcript segments to determine reliability of the coding scheme. When codes were discrepant across coders, researchers discussed discrepancies until overall agreement was equal to or greater than 81 percent, or Cohen's kappa coefficient equal to 0.820 . The final, overall agreement between coders was 83.33 percent (25/30). Obtaining a Cohen's kappa equal to or greater than 0.820 indicated that overall agreement for this coding scheme was higher than would be expected to occur by chance (Landis \& Koch, 1977). Because the initial coding showed high reliability, it was used for the remainder of the study. Themes and sub-themes were closely explored to identify the most significant themes, connections, relationships, and broader significance of the data.

\section{Results and Discussion}

In total, eight hospital staff, five food producers and two food distributors participated in the study. There were ten females and five males in the study and the majority of participants were 45 to 54 years old. Analysis of the interviews identified common themes across the two groups (e.g., hospital staff, and food producers and distributors) involving opportunities and barriers to increasing the role of locally grown foods in hospital food service programs. The two main themes that emerged were commitment to buying and economy of scale for farm-to-hospital partnerships. The main themes and sub-theme elements are described below. Following each set of subthemes are capacity-building strategies that emerged from the in-depth interviews and were further explored by the researchers.

\section{THEME 1: Buying Commitment}

Several significant barriers were identified as reducing buying commitment between local food producers and distributors, and institutions. Barriers included lack of formal contracts, high turnover, limited customer demand, and resources needed for procuring and preparing local foods.

Lack of formal contracts: Local producers identified a lack of consistency in commitment to buying from institutions as a significant challenge to expanding farm-to-institution initiatives in Montana. A local food producer said, "[Institutional buying partners] say 'okay — I'll buy from you this much cabbage at this time. You plant it; I'll be ready to buy it.' And it's not an ironclad contract. It's like, you can grow it and they still might not buy it....So it's more like we all agree to do the best we can and honor this agreement and we'll see where it goes." Small-scale food producers talked about not being in a position to take on a significant level of risk, as unsold products equates to wasted time, labor, space, and money. A food distributor said, "And so right now it's like we don't have growers that necessarily want to make a huge commitment because we don't have institutions who are willing to make the huge commitment. [Food producers] are not in the position just to take these large risks. We can't." Without solid buying commitment from a hospital or other institution, working directly with institutions that have larger food demands is much less feasible for local food producers.

High turnover: Local food producers also identified high turnover in institutions as a barrier to committed buying partnerships. Food producers explained that production planning and seed planting needs to occur early in the spring, and thus farmers need to know what kinds of products institutions will need early in the year. Participants viewed institutional staff and management turnover as associated with sudden changes in menu planning, desired ingredients, and overall communication between the institution and food producer. Producer subjects also perceived staff turnover as entailing extensive time and energy in order to reestablish a working relationship and mutual understanding between producer and institution. A farmer said, "I think another issue is, in terms of the institutions, is turnover. For example, two years ago we grew a lot of lemon cucumbers because the 
[educational institution] really liked them and would buy a lot of them. And then someone in the food buying sector changed and they didn't want to use lemon cucumbers anymore."

Limited customer demand: Hospital staff described limited customer demand as a barrier to selling local food items in their food programs. A lack of enthusiasm for local products and lack of receptiveness to consuming healthier but less familiar menu items can cause dissatisfaction and frustration among customers. Such dissatisfaction has even been seen, at times, to negatively impact sales of particular food items. A participant said, "And you can tell them, 'This [grass fed beef] is good for you.' And they're like, 'Well, I'm not eating a cheese burger because it's good for me.' " Due to the nature of the hospital environment, some patients and visitors crave comfort foods over interest in nutrition education or experimentation with new food ingredients. This sentiment, as well as lack of interest in healthy, local food items, was identified as an obstacle for hospital food management in healthy menu planning and local foods purchasing.

Furthermore, respondents also identified a disconnect in understanding the benefits of consuming local foods as a barrier to increasing demand for these items in the hospital cafeteria setting. Although hospital staff and visitors often recognize the value of a nutritious diet, they often don't understand the benefits of buying and consuming locally. Hospital staff members discussed this challenge, and the process of increasing knowledge and support for using more local foods in hospital and daily diet:

It will be slow though. It takes a lot of time to just plant a seed and then it takes the germination time from someone putting the idea in your head that kale may be a good thing to eat, to going vegan and eating locally. That's a huge shift in someone's life. It's a whole shift in your lifestyle, in your priorities. So I think it's going to be really slow.

If you look at just how hard it is to get your food, to know that your food is safely organic vs. "natural." There's such a knowl- edge barrier for the average consumer who walks into [local grocery store]. You have to teach them what they should be looking for first and why this carrot is better than that carrot and why that's even a priority and why you should spend 45 cents more on this carrot.

\section{Resources needed to procure and prepare} local foods: Hospital staff identified several factors contributing to inconsistent purchasing commitment for local food. For institutions with large food demands, consistent and year-round product availability facilitates more efficient menu planning. Availability of local foods, however, is dependent on seasonality. Hospital staff identified the short Montana growing season as a barrier to using local ingredients. One hospital staff person said, "[Using locally sourced food's] really a challenge in a larger facility and in a state or a climate where you don't have it year round." Large distribution companies, or group purchasing organizations (GPOs), offer a streamlined ordering and delivery process, discounted prices, and processed (e.g., carrots are sliced, artichoke hearts are trimmed and cleaned) food items. Procuring and using local ingredients, however, often requires additional resources not required when working with a GPO. For example, meeting the large-scale hospital demands often means working with multiple local food producers, requiring additional time and resources to establish and maintain the relationships. One hospital staff person said, “A few years ago when the chef's predecessor was trying to do local food, she was trying to deal with the farmers individually and you can't do it. You don't have the time." Moreover, in contrast to prepared and processed food items offered through a GPO contract, planning season-specific menus and processing and preparing local food ingredients were identified as requiring additional input of resources. A hospital staff member commented, "I guess if there were any other challenges, it's the additional labor it takes to prep that stuff. ...I think that would probably be the next step to ease some of the burden on our cook's team and still provide our customers with perhaps more local than we did last year." 
Passionate champion leaders within the institutional setting were identified as a significant enabler of producer-institution relationships. As examples, working with multiple local vendors often results in increased time and effort to procure local foods. Additionally, menu planning based on local and seasonal food items requires time and work. However, kitchen staff most directly involved in food procurement and preparation processes were very willing to accommodate more frequent deliveries, coordinate with multiple vendors, and viewed seasonality as a creative challenge and opportunity, rather than a barrier. This intrinsic enthusiasm and passion for local foods held by kitchen management was identified as supporting institutions in overcoming potential challenges associated with moving away from the streamlined conveniences of a large food distributor and increasing the amount of healthy, local food items used in food service menus. The sentiment of these champion leaders is exemplified by the following:

There's just more appreciation and more of a cognizant thought process once you realize something was local. It just seems like, as much as it's local, it almost seems like it's kind of exotic. So you treat it like that type of an ingredient. You just really treat it the best that you can without doing necessarily too much to it. So I don't think it's a challenge at all, it's just more work on the back hand. But it's something fun, going through some of the offerings they have, some of the seasonal items.

\section{Strategies to address THEME 1: Limited Buying}

\section{Commitment}

A. Cooperative distribution in order to address consistency and availability: The Western Montana Growers Cooperative (WMGC) was identified as a resource that creates market opportunities for direct food producer-hospital relationships. By coordinating with multiple local food producers, WMGC is able to meet larger food quantity demands from institutions, provide more personal relationships with food service management, and customize delivery schedules - benefits hospital staff viewed as invaluable to facilitating increased use of local food in food service meals. A hospital staff person said:

That one contact. It's shocking. They [WMGC] send you the list instead of six emails from six different producers. They're [food producers] funneling all their information through the co-op and the co-op sends that out. You place your order and they bring it to your door. So the communication is great. Knowing what's coming to plan the menu... But yeah, just having all the information in one place, and then one contact saves you six phone calls twice a week probably.

Based on this resource, a capacity-building strategy is to develop more fully the cooperative distribution model. Streamlining the process for institutions to procure locally sourced foods can strengthen capacity to compete with large-scale distributor services (or group purchasing organizations), thus improving institutional buying commitment. Therefore, expanding the visibility of Montana cooperative distributors to institutions, as well as facilitating opportunities for contracts between these two groups, will support the feasibility of using local foods and committing to buy these ingredients.

\section{B. Expand processing facilities to support institutional use of local foods: Expanding} processing could address challenges associated with ease-of-use, and support institutional demand for local food ingredients. For example, producers using the Mission Mountain Food Enterprise Center (MMFEC) can prepare and freeze their food products, enabling them to sell their products year-round. MMFEC infrastructure enables local producers to compete more competitively with large distributors by offering less expensive processed commodity foods. A capacity-building strategy is to expand the Center and its outreach throughout Montana to facilitate greater institutional purchasing of local foods. For example, MMFEC has recently partnered with WMGC to increase the amount of processed local food offered in public schools across the state. Hospital 
staff identified an interest in becoming more familiar with the special services of MMFEC in order to make better use of the facility and further facilitate hospital use of local products. By aggregating produce from a larger number of producers and utilizing "seconds," MMFEC can reduce prices to make local foods more competitive. By processing on-site, MMFEC can also address processing limitations at institutions by delivering a product that is ready to use. Finally, by processing whole vegetables into a variety of products (such as beef taco crumbles or frozen squash chunks), processing can meet consumer demand concerns by producing local food products that have the same appearance and taste as readily available conventional options.

\section{Develop training and networking opportu- nities for staff to increase commitment:}

Worksite-based educational staff programs can help promote a healthy workforce and thereby model healthy behaviors for patients. For example, hospital staff participants identified staff CSA programs as a way to increase nutritional awareness and behaviors among staff. Local and regional programs and cooperatives, such as WMGC, have already begun establishing CSA programs for institutions, so the feasibility to expand such staffbased programs already exists. Education and training workshops for kitchen staff also serves as a feasible strategy in promoting group-wide enthusiasm and support for using locally sourced foods and season-specific menus. Furthermore, educational workshops for hospital administrators may help foster healthier food awareness at the higher, managerial levels and more broadly influence support for farm-to-institution efforts among hospital staff.

Hospital staff also identified connections between institutional chefs as another way to support greater use of local foods in hospital food service meals. For example, chefs could share information and ideas at networking meetings about how to balance the cost of local food ingredients with costs of large distributors more effectively, and how to integrate local foods into hospital food service meals successfully. One hospital staff member described the positive outcome of meeting with other institutions: "So we had that meeting and it was really good that they forced it on me because the [institution] is such they're doing so much more than we are. And they're pulling it off?'

\section{Develop formalized contracts to strengthen farm-institution relationships: Participants} identified formalized contracts between food producers and hospitals as a way for producers to better anticipate future hospital food product demands. Formal contracts can ensure more solid buying commitments and working relationships, and promote a degree of consistency in purchasing. This in turn encourages greater commitment and resource allocation from producers to meet growing needs of institutional markets. One food producer said:

I think the key is that the farmers have to know right now, or really a month ago what we're going to be growing for this season. So those accounts need to be in place and we need to know what these institutions would want so that managers of the Co-op can produce projections, tell everybody what they need and then farms say, "we'll grow this amount." So we just need to know how much to grow and that doesn't always happen early enough.

\section{THEME 2: Economy of Scale for Farm-to- Hospital Partnerships}

As a result of economy of scale, hospital staff and food producers identified several barriers impeding farm-to-institution partnerships. The main barriers were commodity food prices and market saturation.

Commodity food prices: High local food prices were identified as a significant barrier to building capacity for Montana's farm-toinstitution efforts. Our study shows that the systemic challenge of economies of scale and commodity food prices impact the ability of local producers and hospital food service programs to work together. Local producers perceived commodity food prices as inaccurately reflecting actual costs of food. Such a phenomenon is 
associated with economies of scale, where the marginal cost of producing a particular product falls as larger quantities are made (Hamel, n.d.). Without accounting for full production costs, transportation costs, and other externalities, commodity food prices appear highly affordable, making it hard for local producers to compete with such prices. One food producer said:

Part of that is because the cost is lower. So institutional markets, you get a lower cost, generally wholesale you get a lower cost. So you need a higher retail. And I imagine that institutional markets ask for even lower costs than even a lot of the wholesale markets. So that trickling down to the farmer, for us, we wouldn't be able to produce our salad mix for a whole lot cheaper than we're doing now just because we don't have that much space. But if we had 10 acres of salad mix, we could probably do it. So there's an economy of scale there that can be difficult for small farmers.

To further demonstrate this challenge, hospital staff identified the convenience and services of a large distributor as appealing and often more feasible for food service programs which lack resources and infrastructure otherwise needed to process local food ingredients. Due to economy of scale, however, small producers often lack feasible options to process their own products to compete with services of large distributors. One food producer described this challenge:

As a for instance... we take horse trailer trips every other week to [name of Montanabased facility] where we process. So let's say we have four animals on that horse trailer. The mileage, the fuel, the labor to deliver those four animals to [name of Montanabased facility] on a per head basis is about the same as it would take on a per head basis to ship a semi-load to Nebraska. And so there, you know, that cost, when you start thinking about how much difference scale makes, is really big.
Market saturation: Hospital staff perceived lack of availability of local products as a barrier to increasing the amounts of local foods being used in food service meals. Our study found dissonance, however, between the two sets of subjects on perception of availability. Hospital participants generally expressed concern about quantity and the ability of local producers to fill food service needs. For example, one staff member said, "And you just can't hardly get that around here. We would deplete the valley, more or less. And that's an interesting conundrum because why wouldn't we grow enough food for the people who live here?" In response to this concern, food producers instead noted challenges around limited demand and market saturation. Individual community members and institutions committed to local products and supporting the local food system are already engaging in the local food system movement, interacting with local food producers, and purchasing locally sourced ingredients. Local food producers are therefore already filling this committed market's demands. One food producer described this market saturation:

It's this line. Like on one side, there are people who want to buy local food....There are people already aligned with these values and we are killing each other to meet their needs. There are more farm owners than those people need. So there are farmers being left out. The supply is greater than the demand for people in this sphere of values.

Market saturation poses a challenge for producers trying to establish direct working relationships with institutions. At this point, the needs of supportive markets-individuals and local-oriented restaurants—or "low hanging fruit," are being satisfied sufficiently by local producers. Local food production in Montana is beyond the present level of demand for local food ingredients. For example, participants described market saturation in terms of farmers markets as an outlet for local food products. The number of small local producers is so abundant in Montana that competition for business is increasing, which makes farmers markets a less profitable option. A 
dilemma therefore arises in which small producers with limited financial resources are unable to risk large investments to increase production levels until the demand from institutions (such as hospitals, restaurants, and correctional facilities) significantly and committedly increases. Conversely, institutional demand and committed use of local foods cannot increase until levels of production expand to fulfill the large quantity demands of a hospital or other institutional facility.

Strategies to address THEME 2: Economy of Scale on Farm-to-Institution Partnerships

A. Conduct a gap analysis of Montana's food processing infrastructure to understand the gaps in connecting small and mid-sized producers to institutions: Gap analyses are used to determine the steps necessary to move from a current state of function to a greater, more productive state of functioning in the future (Gap Analysis, n.d.). This process creates opportunity to identify strengths and resources currently in place, as well as gaps that need to be filled in order to achieve the desired future state. Conducting a gap analysis would include examining processing, distribution, and aggregation gaps, and could improve institutional capacity to use local foods (Ecotrust, 2015). While MMFEC is an excellent resource, it is one small, rural facility in a large state. However, many hospitals have kitchen infrastructure in place such as food preparation equipment and well-trained kitchen staff that could also be utilized for enhanced processing. Conducting a statewide gap analysis of food processing infrastructure and capacity of hospitals to source and use local foods could provide insight on how to build capacity for more local food processing in Montana. Identifying gaps within both hospital and producer capacity can provide a more systematic assessment and approach to supporting greater competition between locally sourced foods and the prices and conveniences currently associated with commodity food distributors.

\section{B. Develop collaborative problem-solving processes to improve farm-hospital} communication: Dissonance between interview groups suggests that opportunities exist for capacity building and support of direct producerhospital relationships. Local producers identified market saturation as a significant barrier to the growth of Montana's local food system, but also expressed a willingness and readiness to engage with institutions in addressing such challenges. Participants said:

I think that we could definitely solve these problems in institutions if we were thoughtful about how they were approached. If they're on the same page in terms of values, it's pretty easy, we just do logistics.

These people [local producers] are ready. Most of the folks have the land to do it. And we're getting to the point where we have the capability as a cooperative to service these people, to distribute to them, to market to them. It takes a little bit of time I think. The answer to that in short is I think definitely, especially with the number of growers coming onto the scene.

I guess what I'm trying to say is if we're able to be really well organized as a community of growers, we can definitely fulfill the need for the food.

Corresponding capacity-building strategies are networking and collaborative, strategic planning. Networking could help identify ways to overcome misconceptions that local producers and institutions have about working with one another, such as market saturation versus limited availability of food products in relationship to the ability of local producers to fulfill the extensive quantity needs of medical institutions and other large facilities. Creating opportunities for collaborative dialogue between institutions and local producers could ensure that all invested stakeholders are at the table. Additionally, implementing a strategic planning process at an organizational level could facilitate infrastructural change within the hospital setting. Although such reorganization requires collaborative investment and commitment, strategic planning can result in a redistribution of time and management to address more effectively the 
procurement and preparation of locally sourced foods. Through shared investment of a strategic planning model and joint ownership of the process and outcomes, more durable solutions will be generated and implemented in order to increase the amounts of local food used in hospitals (McKinney, 2013). Such a process could resolve misconceptions and challenges currently occurring between local food producers and institutional food services, and further support successful producer-hospital relationships.

\section{Limitations}

Limitations to this study were that information gathered was only specific to experiences of the individuals who participated in the interview process, and that participants might have felt compelled to give socially desirable answers to the interview questions. Additionally, limited participation and reporting findings describing farm-toinstitution challenges and opportunities specific to Montana, render the results less generalizable. However, the capacity building strategies identified in the study could provide a strong basis for building farm-to-institution systems in other areas. Finally, rather than conducting a full triangulation of emergent themes during the data analysis process, only two researchers established coding reliability and agreement.

\section{Future Work}

The study aimed to identify capacity-building strategies for addressing opportunities and challenges to support working relationships between local food producers and hospitals. By exploring the perceptions of both hospital staff and local producers, a situational assessment was developed to describe the strengths and challenges of Montana's farm-to-hospital system. Additional exploration of the strategies and capacity-building opportunities identified from the in-depth interviews will further enhance the validity of the study. For example, developing and conducting a comprehensive survey for additional small- and mid-scale producers would provide insight into the degree to which local food producers truly identify with the established themes.

Montana has a solid local food system and is engaged in the farm-to-table movement. From the in-depth interviews, other hospitals and schools throughout Montana were mentioned as role models successfully engaging in farm-to-fork efforts, and utilizing strengths such as champion leaders and successful, committed partnerships among different institutions and local food producers and distributors. Closer examination of such local initiatives and their successes could contribute to a greater understanding of capacitybuilding strategies relevant to increasing the use of local foods in other Montana institutional food service programs. The aggregated food system, or farming cooperative model (such as WMGC), was also strongly identified in the study by participating producers and food service management as a capacity-building strategy and a significant enabler in moving away from restrictive contracts with large food distributors. Further exploration of the cooperative model and other potentially important strengths or enablers inherent to other non-hospital institutions in using local food ingredients could support broader farm-to-institution relationships and efforts in Montana beyond farm-to-hospital.

Many participants observed that while the use of local foods has increased in the health care cafeteria setting, these efforts haven't transferred to patient meals. This study primarily focused on the identification of barriers and opportunities to using local food ingredients in the cafeteria, with limited reach into using local foods in patient meals. This observation therefore suggests that future work could explore barriers pertaining specifically to the use of local foods in patient meals compared to use in the cafeteria. Additionally, food producer participants identified untapped markets as a significant opportunity for strengthening the farm-to-institution movement beyond farm-to-hospital. For instance, conventional grocery stores have significant potential to support the farm-to-table movement, as large quantities of food quickly and naturally move through these outlets. However, producer and distributor participants perceived these institutions to be a particular challenge for establishing working relationships. Thus, the associated barriers and capacity for establishing contracts between local producers, conventional grocery stores, and other food retail markets 
should be more closely explored to further build successful partnerships within the larger farm-totable movement.

\section{Conclusion}

Collaborative communication and joint problem solving were identified as significant capacitybuilding strategies specific to Montana's farm-toinstitution efforts. However, while collaborative dialogue can decrease misconceptions and support joint problem solving that strengthens farm-toinstitution food systems, collaboration alone will not fully address the identified challenges. It will require institutional and infrastructural build outs, such as further development of food aggregation processes, identification of the most cost and resource-efficient approaches to food processing, and expansion of local cooperative distribution systems. Ultimately, a multi-prong approach to strengthen farm-to-institution food systems will successfully increase the use of locally sourced foods in hospital food service programs.

The main purpose of this study was to identify opportunities and barriers for local producers and hospitals to work together to use more locally sourced foods in food service meals. This study lays the groundwork for more comprehensive efforts to build capacity, and offers insight into particular opportunities and challenges unique to using local foods in institutional systems. Although these findings are specific to Montana producers and institutions, similar concerns and challenges regarding scale are experienced in communities across the country, and are reflected in the established literature exploring farm-to-institution efforts. With similar challenges being faced throughout the country, others could apply our methodology and approach to further explore ways to strengthen farm-to-institution systems. Conducting a gap analysis to better connect small and mid-sized producers to the local institutional systems, strengthening locally based aggregated food systems for greater purchasing efficiency, and exploring collaborative and mutually beneficial relationships for greater communication and problem-solving, may therefore provide a framework for building farm-to-institution efforts in other communities beyond Montana.

\section{Acknowledgments}

We would like to acknowledge the following people for their contributions to this research. We would like to acknowledge Ms. Perline's thesis committee chair, Dr. Blakely Brown, for continual guidance and feedback throughout this process. Dr. Brown's commitment and investment drove this study and facilitated the completion of the project. We would also like to acknowledge Perline's thesis committee members, Dr. Annie Sondag and Annie Heuscher, who graciously took the time to review the study's design, instruments and ongoing progress. A special thanks also goes to Carly Holman and Vernon Grant for their assistance with the research process. Above all, we would like to thank the study participants for taking time out of their busy schedules to share their personal thoughts and experiences. This study would not have been possible without their help.

\section{References}

Cohen, G. (2006, September). First, do no harm. Paper presented at conference Designing the $21^{\text {st }}$ Century Hospital: Environmental Leadership for Healthier Patients and Facilities, Hackensack, New Jersey. Retrieved from https://www.healthdesign.org/ chd/research/first-do-no-harm

Community Medical Center. (n.d.-a). About us.

Retrieved June 2015 from

http://communitymed.org/contact/about-us

Community Medical Center. (n.d.-b). Big Sky Café.

Retrieved June 2015 from

http://communitymed.org/resources/big-sky-cafe

Conner, D. S., Sevoian, N., Heiss, S. N., \& Berlin, L. (2014). The diverse values and motivations of Vermont farm to institution supply chain actors. Journal of Agricultural and Environmental Ethics, 27(5), 695-713. http://dx.doi.org/10.1007/s10806-0139485-4

Cromp, D., Cheadle, A., Solomon, L., Maring, P., Wong, E., \& Reed, K. M. (2012). Kaiser Permanente's farmers' market program: Description, impact, and lessons learned. Journal of Agriculture, Food Systems, and Community Development, 2(2), 29-36. http://dx.doi.org/10.5304/jafscd.2012.022.010 
Dauner, K. N., Lacaille, L. J., Schultz, J. F., Harvie, J., Klingner, J., Lacaille, R., \& Branovan, M. (2011). Implementing healthy and sustainable food practices in a hospital cafeteria: A qualitative look at processes, barriers, and facilitators of implementation. Journal of Hunger and Environmental Nutrition, 6(3), 264-278. http://dx.doi.org/10.1080/19320248.2011.597828

Ecotrust. (2015). Oregon food infrastructure gap analysis: Where could investment catalyze regional food system growth and development? Ecotrust, Portland, Oregon. Retrieved from http://www.ecotrust.org/media/ Food-Infrastructure-Gap-Report1.pdf

Gap Analysis. (n.d.).In Businessdictionary.com. Retrieved from http://www.businessdictionary.com/ definition/gap-analysis.html

Gregoire, M. B., Arendt, S. W., \& Strohbehn, C. (2005). Iowa producers' perceived benefits and obstacles in marketing to local restaurants and institutional foodservice operations. Journal of Extension, 43(1), 34-42. Retrieved from http://www.joe.org/joe/2005february/rb1.php

Hamel, G. (n.d.). Problems of small scale industries. Small Business Chronicles. Retrieved from http://smallbusiness.chron.com/problems-smallscale-industries-18186.html

Ikerd, J. E. (2009). Current status and future trends in American agriculture: Farming with grass. In A. J. Franzluebbers (Ed.), Farming with grass: Achieving sustainable mixed agricultural landscapes (pp. 12-25). Ankeny, Iowa: Soil and Water Conservation Society. Retrieved from http://web.missouri.edu/ ikerdj/papers/Oklahoma $\% 20$ Farming $\% 20$ with $\% 20 \mathrm{Grass} \% 20-\% 20$ Status $\% 20 \% 20$ Trends.htm

Kloppenburg, J., Wubben, D., \& Grunes, M. (2008). Linking the land and the lunchroom: Lessons from the Wisconsin Homegrown Lunch Project. Journal of Hunger and Environmental Nutrition, 3(4), 440-455. http://dx.doi.org/10.1080/19320240802529300

Kulick, M. (2005). Healthy food, healthy hospitals, healthy communities: Stories of health care leaders bringing fresher, bealthier food choices to their patients, staff and community. Minneapolis, Minnesota: Institute for Agriculture and Trade Policy. Retrieved from http://noharm. org/lib/downloads/food/Healthy Food Hosp Comm.pdf

Landis, J. R., \& Koch, G. G. (1977). The measurement of observer agreement for categorical data. Biometrics, 33(1), 159-174. http://dx.doi.org/10.2307/2529310

Lobao, L., \& Stofferahn, C. W. (2008). The community effects of industrialized farming: Social science research and challenges to corporate farming laws. Agriculture and Human Values, 25(2), 219-240. http://dx.doi.org/10.1007/s10460-007-9107-8

Lyson, T. A., \& Green, J. (1999). The agricultural marketscape: A framework for sustaining agriculture and communities in the Northeast. Journal of Sustainable Agriculture, 15(2-3), 133-150. http://dx.doi.org/10.1300/J064v15n02 12

McKinney, M. (2013). A primer on natural resources conflict resolution. Missoula: University of Montana, Center for Natural Resources and Environmental Policy. Retrieved from http://www.umt.edu/mansfield/internationalprogr ams/susi/Readings $\% 20$ and $\% 20$ Resources/naturalresources-conflict-resolution.pdf

Penrod, J., Preston, D. B., Cain, R. E., \& Starks, M. T. (2003). A discussion of chain referral as a method of sampling hard-to-reach populations. Journal of Transcultural Nursing, 14(2), 100-107. http://dx.doi.org/10.1177/1043659602250614

Raison, B., \& Scheer, S. D. (2015). Potential of local food use in the Ohio health care industry: An exploratory study. Journal of Agriculture, Food Systems, and Community Development, 5(3), 131-147. http://dx.doi.org/10.5304/jafscd.2015.053.011 St. Patrick Hospital. (n.d.). About St. Patrick Hospital. Retrieved in June 2015 from Providence Health \& Services website: http://montana.providence.org/ hospitals/st-patrick/about/ 